\title{
Synthetic graphite production of oil palm trunk chip at various heating rate via pyrolisis process
}

\begin{abstract}
Synthetic graphite was synthesized from oil palm trunk chip in controlled heating condition or pyrolysis process. The heating rate $(5 \% \mathrm{~min}, 10 \% \mathrm{~min}$ and $20 \% \mathrm{~min})$ were varied whilst the heating temperature at $800{ }^{\circ} \mathrm{C}$ was fixed. After heat treatment process, the samples were characterized by X-Ray Diffraction (XRD) and analyzed using X'Pert Highscore Plus software. Graphite phase was analysed by XRD and it was further supported by RAMAN spectroscopy analysis to confirm the graphitic nature of the synthetic graphite obtained. The morphological study was carried out by using Scanning Electron Microscope (SEM). Based on the analysis, it was confirm that synthetic graphite was successfully synthesized by heat treatment at $800{ }^{\circ} \mathrm{C}(20 \% \mathrm{~min}$ heating rate). Synthetic graphite were observed in the form of amorphous carbon based on the XRD diffraction pattern that match with the reference code of 00-041-1487. RAMAN spectroscopy also showed the formation on D, G and 2D peaks at the respective wavenumber of $1250 \mathrm{~cm}-1,1625 \mathrm{~cm}-1$ and $2700 \mathrm{~cm}-1$.
\end{abstract}

Keyword: Synthetic graphite; Oil palm trunk; Pyrolysis; Graphene; Graphene oxide 